\title{
ATRIP protects progenitor cells against DNA damage in vivo
}

\author{
Gabriel E. Matos-Rodrigues (10 ${ }^{1,5}$, Paulius Grigaravicius ${ }^{2,6}$, Bernard S. Lopez ${ }^{3}$, Thomas G. Hofmann ${ }^{4}$, \\ Pierre-Olivier Frappart (1) ${ }^{4}$ and Rodrigo A. P. Martins (1)
}

\begin{abstract}
The maintenance of genomic stability during the cell cycle of progenitor cells is essential for the faithful transmission of genetic information. Mutations in genes that ensure genome stability lead to human developmental syndromes. Mutations in Ataxia Telangiectasia and Rad3-related (ATR) or in ATR-interacting protein (ATRIP) lead to Seckel syndrome, which is characterized by developmental malformations and short life expectancy. While the roles of ATR in replicative stress response and chromosomal segregation are well established, it is unknown how ATRIP contributes to maintaining genomic stability in progenitor cells in vivo. Here, we generated the first mouse model to investigate ATRIP function. Conditional inactivation of Atrip in progenitor cells of the CNS and eye led to microcephaly, microphthalmia and postnatal lethality. To understand the mechanisms underlying these malformations, we used lens progenitor cells as a model and found that ATRIP loss promotes replicative stress and TP53-dependent cell death. Trp53 inactivation in Atripdeficient progenitor cells rescued apoptosis, but increased mitotic DNA damage and mitotic defects. Our findings demonstrate an essential role of ATRIP in preventing DNA damage accumulation during unchallenged replication.
\end{abstract}

\section{Introduction}

Genomic stability is crucial for cellular and tissue homeostasis, normal development, and the prevention of tumorigenesis and aging. Mutations in genes that ensure genome stability and proper chromosomal segregation lead to human developmental syndromes ${ }^{1,2}$. DNA damage response (DDR) pathways sense, signal and repair different types of DNA damage and are crucial for maintaining genomic stability ${ }^{3}$. The Ataxia Telangiectasia and Rad3related (ATR) kinase regulates replication fork firing and stability to ensure the proper timing of DNA replication during S-phase and cell cycle checkpoints to prevent mitosis in cells with under-replicated $\mathrm{DNA}^{4,5}$. When single-stranded DNA (ssDNA) is exposed at DNA damage

\footnotetext{
Correspondence: Pierre-Olivier Frappart (pfrappar@uni-mainz.de) or Rodrigo A.P. Martins (rodrigo.martins@icb.ufr..br)

${ }^{1}$ Programa de Biologia Celular e do Desenvolvimento, Instituto de Ciências Biomédicas, Universidade Federal do Rio de Janeiro, Rio de Janeiro, RJ, Brazil ${ }^{2}$ Clinical Cooperation Unit Neuropathology, German Cancer Research Center (DKFZ), D-69120 Heidelberg, Germany

Full list of author information is available at the end of the article

Edited by I. Amelio
}

sites or replication forks, RPA-coated ssDNA recruits ATR-interacting protein (ATRIP) and activates ATR, which coordinates a replicative stress response $(\mathrm{RSR})^{6,7}$. ATR protein stability and activity as well as all the described functions of ATR depend on ATRIP ${ }^{6,8}$.

In humans, mutations in ATR or ATRIP lead to Seckel syndrome, which is characterized by growth defects, neurodevelopmental malformations and short life expectancy ${ }^{1}$. Mouse models of ATR loss of function have highlighted the essential contribution of ATR to development. While Atr germline inactivation leads to early embryonic lethality ${ }^{9,10}$, conditional knockout mice have revealed that ATR plays essential roles in proper cell cycle progression, genome stability and meiosis ${ }^{11-14}$. In addition, hypomorphic Atr mutations in mice recapitulate some of the developmental defects observed in Seckel syndrome patients ${ }^{15}$. Although the contribution of ATR to genomic stability and appropriate development has been extensively investigated, the function of ATRIP in vivo is unknown.

\section{(c) The Author(s) 2020}

(c) (i) Open Access This article is licensed under a Creative Commons Attribution 4.0 International License, which permits use, sharing, adaptation, distribution and reproduction c. in any medium or format, as long as you give appropriate credit to the original author(s) and the source, provide a link to the Creative Commons license, and indicate if changes were made. The images or other third party material in this article are included in the article's Creative Commons license, unless indicated otherwise in a credit line to the material. If material is not included in the article's Creative Commons license and your intended use is not permitted by statutory regulation or exceeds the permitted use, you will need to obtain permission directly from the copyright holder. To view a copy of this license, visit http://creativecommons.org/licenses/by/4.0/. 
The accumulation of DNA damage can activate the tumor suppressor protein TP53, a master regulator of the DDR that regulates cell cycle arrest, apoptosis, cell metabolism and DNA repair ${ }^{16,17}$. Moreover, inactivation of DDR-related genes may lead to TP53-dependent apoptosis ${ }^{17,18}$. Notably, Atr inactivation increases spontaneous DNA damage, but the simultaneous inactivation of Atr and Trp53 in mouse neural progenitor cells (NPCs) does not rescue brain growth defects ${ }^{12,19}$. Additionally, TP53-inactivated cancer cells are particularly sensitive to ATR signaling inhibition ${ }^{20-22}$, suggesting that ATR and TP53 work in parallel to prevent DNA damage accumulation. Indeed, Trp53 inactivation in hypomorphic Atrmutated mice leads to synthetic lethality ${ }^{15}$. This evidence suggests cooperation between the ATRIP-ATR signaling pathway and Trp53; however, the synergy between these pathways during the cell cycle progression of unchallenged progenitor cells is not completely understood.

Here, we developed a new mouse model to investigate the function of ATRIP. We showed that the tissue-specific inactivation of Atrip during CNS and eye development led to severe growth defects that were associated with the death of progenitor cells. Next, due to its wellcharacterized developmental kinetics and cell cycle dynamics $^{23}$, we used the developing lens as a model to better understand the cellular and molecular outcomes of Atrip inactivation in vivo. Importantly, the developing lens was particularly useful for probing the cross-talk between $\operatorname{Tr} 553$ and other tumor suppressor genes ${ }^{24}$. Atrip inactivation led to replicative stress, DNA damage accumulation and TP53-dependent apoptosis. Interestingly, while Trp53 inactivation rescued the apoptosis of Atripdeficient lens progenitor cells, it increased mitotic defects and did not rescue the observed microphthalmia. Taken together, these results reveal essential roles of ATRIP for DNA damage avoidance and progenitor cell homeostasis during development.

\section{Materials and methods Mice}

The experimental procedures involving animals were approved by the Committee of Ethics in Animal Use of the Health Science Center (CEUA/CCS) of Brazil and approved by the governmental review board of BadenWürttemberg, Germany (Regierungspräsidium KarlsruheAbteilung 3-Landwirtschaft, Ländlicher Raum, Veterinärund Lebensmittelwesen).

The generation of Atrip $^{\text {Flox }}$ mice was performed as follows. The targeting vector was constructed using the recombineering method developed by the National Cancer Institute (USA). The BAC containing Atrip was obtained from the Wellcome Trust Sanger Institute (bMQ-176B24). Exons 1, 2 and 3 of Atrip were targeted since the deletion of these exons was predicted to abrogate protein translation. One LoxP site was inserted upstream of exon 1, and the pGK-neo cassette flanked by two Frt sites followed by a second LoxP was inserted between exons 3 and 4. Prior to E14.1 ES cell electroporation, the targeting vector was linearized (NotI), and proper targeting was verified by restriction mapping and sequencing. After 12 days, 384 individual clones were analyzed by Southern blotting (with EcoRI digestion and a genomic probe), and 15 clones (3.9\%) presented the expected targeting event. The presence of the third LoxP site was confirmed by PCR in 6 clones (Fig. 1). The pGKneo cassette was excised in vivo to generate the Atrip floxed allele using the FLPe mouse.

Nestin-Cre (B6. Cg- Tg(Nes-cre) $1 \mathrm{Kln} / \mathrm{J})$, Lens-Cre (Tg (Pax6-cre,GFP)1Pgr), Trp53 floxed (FVB.129Trp53tm1Brn) and FLPe (B6;SJL-Tg(ACTFLPe)9205Dym/ J) mice were purchased from Jackson Laboratory. The control group (Atrip ${ }^{\text {Ctrl }}$ ) was composed of Atrip $^{+/+}$, Atrip $^{+/}$ Flox and Atrip ${ }^{\text {Flox/Flox }}$ mice. Homozygous or heterozygous inactivation of Atrip using Nestin-Cre were respectively identified as Atrip $^{\text {Het }}=$ Atrip $^{\text {Flox/Flox; }}$ Nestin-Cre ${ }^{+/-}$or Atrip $^{\text {Nes-Cre }}=$ Atrip $^{+/ \text {Flox }} ;$ Nestin-Cre ${ }^{+/-}$. Mice in which Atrip and Trp53 were homozygously inactivated using Nestin-Cre were identified as Atrip;Trp $53^{\text {Nes-Cre }}=$ Atrip $^{\text {Flox }}$ ${ }^{\text {Flox }}$; Trp53 ${ }^{\text {Flox/Flox }}$; Nestin-Cre ${ }^{+/-}$. Mice in which Trp53 was homozygously inactivated using Nestin-Cre were identified as $\quad \operatorname{Trp} 53^{\text {Nes-Cre }}=\operatorname{Trp} 53^{\text {Flox/Flox }} ;$ Nestin-Cre ${ }^{+/-}$. Homozygous inactivation of Atrip in the surface ectoderm using Le-Cre was identified as Atrip ${ }^{\text {Le-Cre }}=$ Atrip $^{\text {Flox/Flox }} ; \mathrm{Le}^{-\mathrm{Cre}^{++}}$ (Supplementary Fig. 2).

\section{RNA extraction, CDNA synthesis and real-time RT-PCR}

Lenses from three different mice of the same litter were dissected in cold PBS and lysed in $1 \mathrm{~mL}$ of TRIzol (Life/ Thermo Fisher, Cat\# 15596026), and RNA extraction was performed as previously described ${ }^{25}$.

Real-time RT-PCR was performed in 96-well optic plates (Applied Biosystems, N801-0560) in an Applied Biosystems ABI7500 thermocycler. The following primers were used for real-time RT-PCR: SYBR primers, ATR forward 5'-TGCTATTCAGGAGTTGCTTTCT- $3^{\prime}$ and reverse $5^{\prime}$ GGACATGCTCAGGGAATCTTT- $3^{\prime}$ and Atrip forward 5'-TCTCCAGAAAGCTCCAATCAC-3'; TaqMan primers and probe, GPI1 forward $5^{\prime}$-TCCGTGTCCCTT CTCACCAT- $3^{\prime}$, reverse 5'-GGCAGTTCCAGACCAGCT TCT- $3^{\prime}$, and probe $5^{\prime}$-CTCCCTGCCCAGAGCGCACC- $3^{\prime}$ and $\beta$-actin forward $5^{\prime}$-AGCCACCCCCACTCCTAAGA$3^{\prime}$, reverse 5'-TAATTTACACAGAAGCAATGCTGTCA$3^{\prime}$, and probe $5^{\prime}$-ATGGTCGCGTCCATGCCCTGA- $3^{\prime}$. Each sample was run in duplicate, and only duplicates showing a variation of less than $0.5 \mathrm{Ct}$ were further analyzed. The comparative Delta-Delta Ct (2- $\Delta \Delta \mathrm{Ct})$ method for relative quantification was applied to determine the relative quantity of a target compared to the average of the 


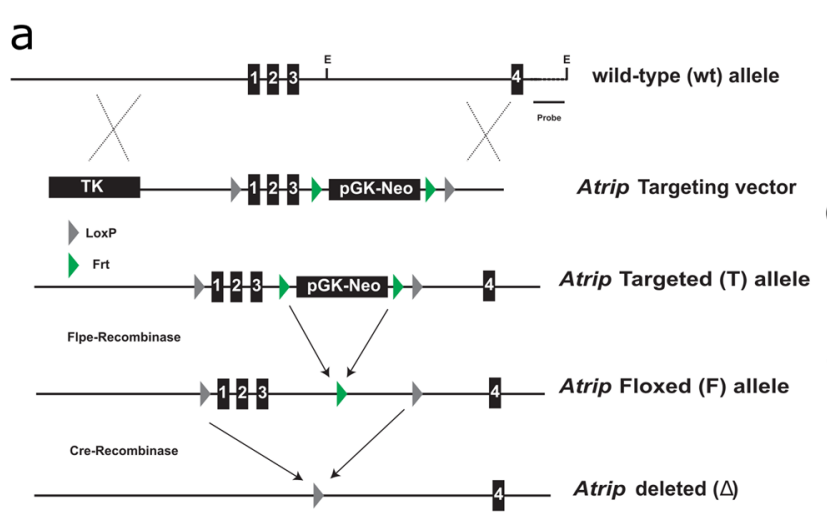

b

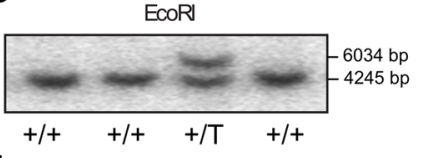

C

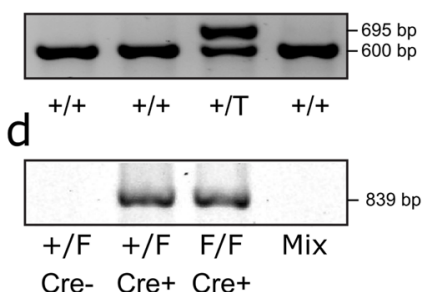

e
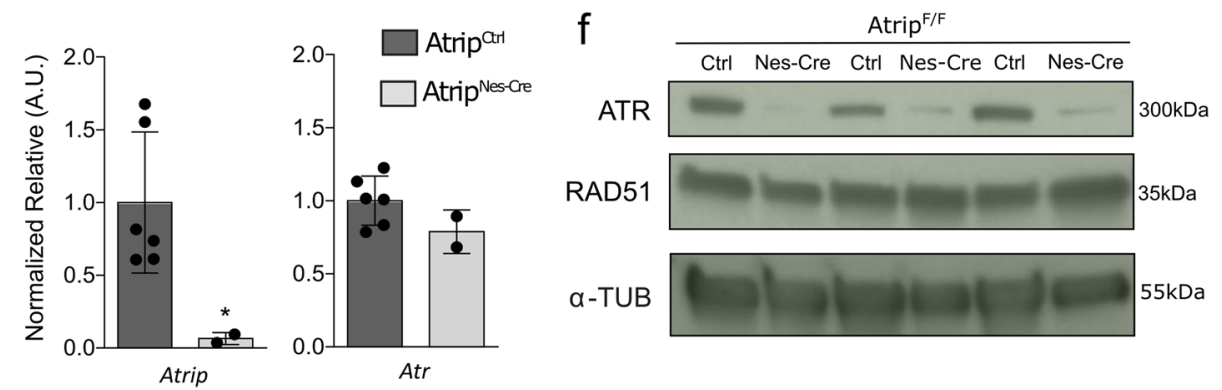

Fig. 1 Generation of Atrip conditional knockout mice. a Gene-targeting strategy for the Atrip gene. The LoxP sequences flanking the three first exons of Atrip enable its genetic inactivation following Cre-mediated recombination. The pGK-Neo region of the transgene was excised in vivo using FLPe recombinase. $\mathbf{b}$ Southern blot generated using a genomic probe targeting intron 4 and digestion with EcoRl. $\mathbf{c}$ PCR amplification of the third LoxP site located upstream of exon 1. d PCR analysis of the Nestin-Cre-mediated recombination of the Atrip ${ }^{\text {flox }}$ transgene in Atrip ${ }^{\text {Nes-Cre }}$ cortex. e Atrip $^{\text {. }}$ and Atr mRNA expression analysis by real-time RT-PCR using cortex samples from Atrip ${ }^{\text {Ctrl }}$ and Atrip ${ }^{\text {Nes-Cre }}$ mice at E17.5. The number of biological samples analyzed is represented as the dots in the graphs. Error bars indicate SEM; ${ }^{*} p<0.05$. $\mathbf{f}$ Western blot of independent Atrip ${ }^{\mathrm{Ctrl}}$ and Atrip ${ }^{\mathrm{Nes}-\mathrm{Cre}}$ cortex samples at E17.5.

two reference genes (GPI1 and $\beta$-actin). We employed a mathematical correction similar to QBASE software based on the use of the mean $\Delta \mathrm{Ct}$ of all groups to define the calibrator (Hellemans et al.).

\section{Volume measurements of the eye}

The volumes of postnatal and adult eyes were measured as previously described ${ }^{26}$.

\section{Histology and immunofluorescence}

Histological analyses were performed in cryosections. Embryo heads were fixed in $4 \%$ PBS-buffered paraformaldehyde for $24 \mathrm{~h}$ at $4{ }^{\circ} \mathrm{C}$ and cryoprotected in 10,20 and 30\% (overnight) PBS-buffered sucrose solutions. Sections of $10 \mu \mathrm{m}$ were obtained using a Leica 1850 cryostat.

Slides were washed with PBS, and antigen retrieval was performed using citrate buffer $(\mathrm{pH}=6)$. The following antibodies and dilutions were used: anti-Ser10 pH3 (1:50, Cell Signaling, cat\# 9701), anti-active caspase-3 (1:100, BD Biosciences, cat\#: 559565), anti- $\gamma \mathrm{H} 2 \mathrm{AX}$ (1:300, Millipore, cat\# 05-636), anti- $\gamma \mathrm{H} 2 \mathrm{AX}$ (1:200, Abcam, cat\# ab11174), anti-BrdU (1:3, General Electric, cat\# RPN20), anti-Trp53
(CM5, 1:300, Vector Laboratories, cat\# VP-P956), and anti-phospho TP53 (Ser15) (1:100, Cell Signaling Technology, \#9284S).

Immunofluorescence reactions were developed via different methods, involving the use of a biotinylated secondary antibody followed by an $\mathrm{ABC}$ complex and Cy3tyramide kit (Perkin Elmer, cat\#: FP1046) or an Alexa secondary antibody (1:500, Invitrogen). Fluorescent nuclear counterstaining was performed using DAPI (Lonza, cat\#: PA3013).

To label S-phase cells in vivo, intraperitoneal injections of $50 \mu \mathrm{g} / \mathrm{g}$ of body weight of BrdU (Sigma Aldrich, cat\# B5002) were performed. Embryos were collected $1 \mathrm{~h}$ after injection. TUNEL analysis was performed following the manufacturer's instructions (Promega, cat\# G7362). Fluorescent images were captured using a Leica TCS-SP5 with an AOBS system.

\section{Western blot analysis}

Protein extraction and SDS-PAGE protein separation were performed as previously reported ${ }^{27}$. Primary antibodies for the following target proteins were used: ATR (1:500, Santa Cruz Biotechnology, cat\# SC1887) and 
$\alpha$-tubulin (1:10000, Santa Cruz, cat \#: sc32293). HRPconjugated secondary antibodies from Cell Signaling were employed (1:1000, anti-mouse IgG, cat \#: 7076, anti-rabbit IgG, cat \#: 7074). The ECL system (cat \#: RPN2132) was used according to the manufacturer's instructions, and chemiluminescence was captured using ChemiDoc MP (BioRad) equipment.

\section{Statistical analysis}

GraphPad Prism software was used for statistical analysis. The $t$-test, one-way ANOVA and two-way ANOVA were performed as indicated. The reported $p$-values are based on two-sided tests. Standard methods (http:// powerandsamplesize.com/) were applied to determine the power to detect a pre-specified effect size. Mice were allocated to experimental groups in accordance to their genotypes. The experimenters were blind in relation to the genotype of the experimental groups in few experiments.

\section{Results}

ATRIP loss in CNS causes microcephaly, microphthalmia and premature lethality

To understand the function of ATRIP in vivo, we generated an Atrip conditional knockout mouse in which the first three exons of the Atrip gene were flanked by LoxP sequences $\left(\right.$ Atrip $\left.^{\text {Flox }}\right)$ (Fig. 1a). Three Atrip-targeted ES cell clones verified by Southern blotting were injected into blastocysts, and 12 chimeras with a high percentage of chimerism were obtained. Germline transmission was confirmed by Southern blotting and PCR (Fig. 1b, c). To inactivate Atrip in progenitor cells of the developing CNS and eye, we generated Nestin-Cre; Atrip ${ }^{\text {Flox/Flox }}$ mice $\left(\right.$ Atrip $\left.^{\text {Nes-Cre }}\right)$. We confirmed genomic recombination by PCR (Fig. 1d) and decreased Atrip mRNA expression by real-time RT-PCR (Fig. 1e). Interestingly, while no difference in Atr mRNA levels was detected in the cortex of Atrip $^{\text {Nes-Cre }}$ mice at embryonic day 17.5 (E17.5) (Fig. 1e), a decrease in the ATR protein content was evident. In contrast, RAD51, a homologous recombination protein also expressed in dividing cells ${ }^{28}$, but unrelated to the ATRIP/ATR complex, did not change in Atrip-deficient cortex (Fig. 1f). These data indicate that, as previously described in cell lines ${ }^{8,29}$, ATRIP is essential for ATR protein stability in NPCs in vivo.

The inactivation of Atrip in the CNS and eye did not change the Mendelian ratio at birth (Atrip ${ }^{\text {Nes-Cre }}$ : $25 \%$ expected and 35\% [9/26] observed). In comparison to Atrip $^{\text {Ctrl }}$ and Atrip ${ }^{\text {Het }}$, the Atrip ${ }^{\text {Nes-Cre }}$ mice exhibited a reduced body mass (Fig. 2a), microcephaly and decreased eye volume (microphthalmia) (Fig. 2b, c). Histological analysis of the brain at postnatal day 7 (P7) revealed a profound developmental growth impairment of the cortex, cerebellum, hippocampus and dorsal striatum (Supplementary Fig. 1) that was associated with postnatal lethality around P9. Notably, these phenotypes mirror the developmental defects observed in mice with an Atrdeficient $\mathrm{CNS}^{12}$. a

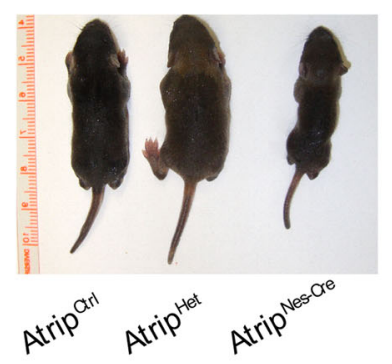

C

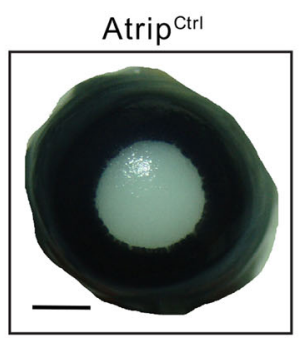

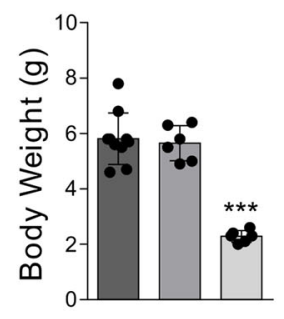

b
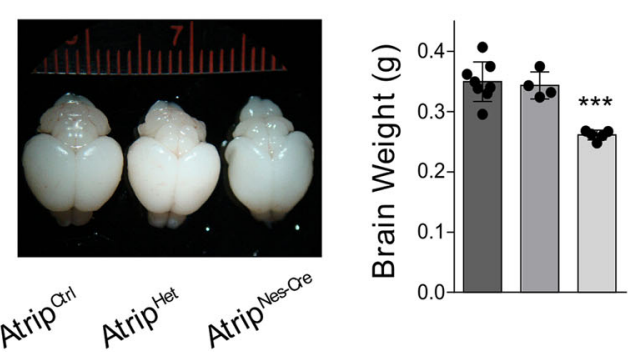
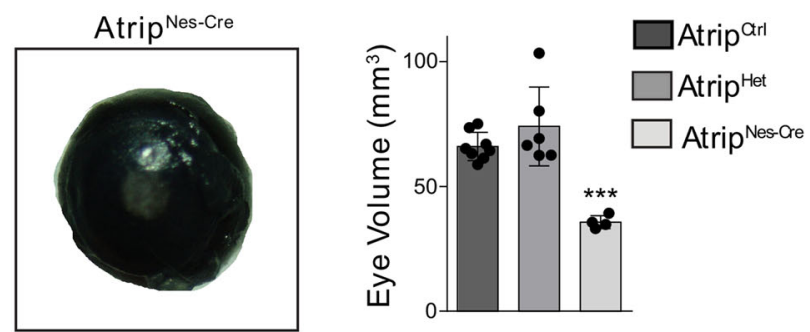

Fig. 2 Atrip is essential for eye development. a, b Representative images of the body (a) and brain (b) and quantification of their weights in

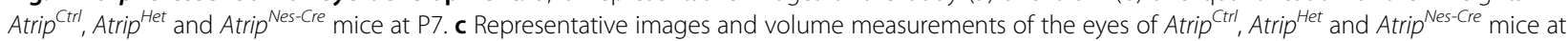
P7. Statistical analysis: one-way ANOVA followed by the Newman-Keuls posttest. The number of biological samples analyzed is represented as the dots in the graphs. Error bars indicate SEM; ${ }^{* *} p<0.001$. 


\section{ATRIP loss in early stages of eye development leads to aphakia}

To confirm the importance of Atrip specifically for eye development, we generated Atrip ${ }^{\text {Le-Cre }}$ (Atrip ${ }^{\text {Flox/Flox }}$; Le$\left.\mathrm{Cr}^{+/-}\right)$mice, in which LoxP site recombination occurs in earlier stages of lens formation ${ }^{30}$. ATRIP loss in the surface ectoderm (E9) led to aphakia (absence of lens) and eye growth defects $(\sim 80 \%$ reduction in eye volume at P21) (Supplementary Fig. 2). Altogether, these findings reveal an essential function of Atrip for lens and eye development.

\section{ATRIP loss induces the cell death of progenitor cells}

To understand the function of ATRIP in vivo, we focused our analysis on lens development, because this tissue is formed by only one type of progenitor cell with well-characterized cell cycle progression. Gene expression analysis of Atrip and Atr in the developing mouse lens revealed that both transcripts are found as early as E12.5 and exhibit similar expression patterns (Supplementary Fig. 3). To investigate how ATRIP loss affects lens progenitor cells homeostasis, we analyzed the morphology, cell proliferation and cell death of Atrip ${ }^{\text {Nes-Cre }}$ lenses. In lens progenitor cells, Nestin-Cre-mediated recombination occurs around E12.5-E13.5 $5^{31}$. At this developmental stage, the lens anterior epithelium is composed of progenitor cells that proliferate and migrate towards the equatorial region, where they exit the cell cycle and differentiate to form fiber cells ${ }^{32,33}$ (Fig. 3a).

Analysis of the Atrip-deficient postnatal lens revealed remarkable developmental defects and tissue disorganization. At P7, Ki67 staining indicated a reduction in the progenitor cells in Atrip ${ }^{\text {Nes-Cre }}$ lenses (Supplementary Fig. 4a). In the developing lens, cyclin D1 is expressed in the transition zone cells, where cells move from the anterior epithelia and start differentiation into fiber cells $^{23}$. Atrip ${ }^{\text {Nes-Cre }}$ lens present an abnormal organization transition zone as revealed by cyclin D1 staining (Supplementary Fig. 4b). Terminal differentiation of lens fiber cells requires organelles and nuclei degradation leading to the formation of the organelle free zone (OFZ), that is identified by the absence of nuclei ${ }^{23}$. In the lens, nuclei degradation during fiber cell differentiation is marked by $\gamma \mathrm{H} 2 \mathrm{AX}$. Atrip ${ }^{\text {Nes-Cre }}$ lens lack an OFZ and present a disorganized pattern of $\gamma \mathrm{H} 2 \mathrm{AX}$ - staining (Supplementary Fig. 4c). These results show that Nestin-Cre-mediated loss of ATRIP in the lens progenitor cells severely impact lens tissue morphology.

To better understand the compromised morphogenesis of Atrip ${ }^{\text {Nes-Cre }}$ lens, we evaluated the impact of Atrip inactivation on the cellular basis of lens embryogenesis. Given the role of the ATRIP-ATR complex in the DNA damage response, we first asked whether Atrip deficiency induces the accumulation of DNA damage specifically in the progenitor cells of the lens epithelia. At E17.5, the quantification of $\gamma \mathrm{H} 2 \mathrm{AX}$-positive $(\gamma \mathrm{H} 2 \mathrm{AX}+)$ cells revealed a marked $\sim 45$-fold increase in the proportion of $\gamma \mathrm{H} 2 \mathrm{AX}+$ cells in Atrip-deficient progenitor cells (Fig. 3b). ATRIP loss also dramatically increased cell death, as revealed by the presence of TUNEL + cells in the Atrip ${ }^{\text {Nes-Cre }}$ lens at E17.5 (Fig. 3c). Consistent with apoptotic cell death, a $\sim 30$ fold increase in the proportion of cleaved caspase-3 (cCasp3)-positive cells was observed in Atrip-deficient lens epithelia (Fig. 3d).

To test whether the proliferation rate of lens progenitor cells is affected by ATRIP loss in vivo, we scored the proportion of S-phase cells (BrdU+) in Atrip ${ }^{\text {Nes-Cre }}$ and Atrip ${ }^{C t r l}$ lenses. No difference in the number of BrdUincorporating cells was observed at E17.5 (Fig. 3e). In addition, no change in the proportion of mitotic cells, as revealed by phospho-histone $\mathrm{H} 3$ ( $\mathrm{pH} 3$ ) staining, was observed in Atrip-deficient progenitors (Fig. 3f). These findings suggest that the ATRIP-ATR signaling pathway is key to preventing DNA damage accumulation and apoptosis in progenitor cells.

\section{Cell death induced by Atrip inactivation is TP53 dependent}

DNA damage induces the stabilization of TRP53 and TRP53-mediated cell death (Meek, 2009). We asked whether the observed accumulation of DNA damage in Atripdeficient lens progenitor cells leads to TRP53 stabilization and/or TRP53-mediated cell death. Immunostaining for total TRP53 revealed its stabilization in Atrip-deficient lens progenitor cells (Fig. 4a, b). The phosphorylation of TRP53 (human S15/mouse S18) by PI3K-like kinases, such as ATM and ATR, is a well-characterized mechanism of TRP53 stabilization ${ }^{34,35}$. Consistent with the absence of TRP53 staining in control progenitor cells and with a phosphorylation-dependent stabilization of TRP53, phospho-TRP53+ progenitor cells were exclusively found in the Atrip ${ }^{\text {Nes-Cre }}$ lens (Fig. 4c).

TRP53 stabilization following DNA damage often results in TRP53-dependent cell cycle arrest and/or apoptosis (Meek, 2009). To test whether TRP53 mediates cell death following ATRIP loss, we generated doubledeficient Atrip/Trp53 mice (Atrip ${ }^{\text {Flox/Flox; }}$ Trp $53^{\text {Flox } / \text { Flox }}$; Nestin-Cre ${ }^{+/-}$, referred to as Atrip; Trp $53^{\text {Nes-Cre }}$ or cDKO). First, we evaluated whether Trp53 inactivation affects cell cycle progression in Atrip-deficient lens. Quantification of S-phase (BrdU+) and mitotic cells ( $\mathrm{pH} 3$ +) revealed no difference between Atrip ${ }^{\text {Nes-Cre }}$ and Atrip; Trp53 $3^{\text {Nes-Cre }}$ mice at E15.5 (Fig. 5a, b), suggesting that TRP53 does not alter cell cycle progression following ATRIP loss. In contrast, as verified by the TUNEL assay (Fig. 5c) and cCasp3 staining (Fig. 5d), the inactivation of Trp53 prevented the cell death induced by ATRIP loss. Therefore, we conclude that TRP53 is required for the apoptosis of Atrip-deficient progenitor cells. 

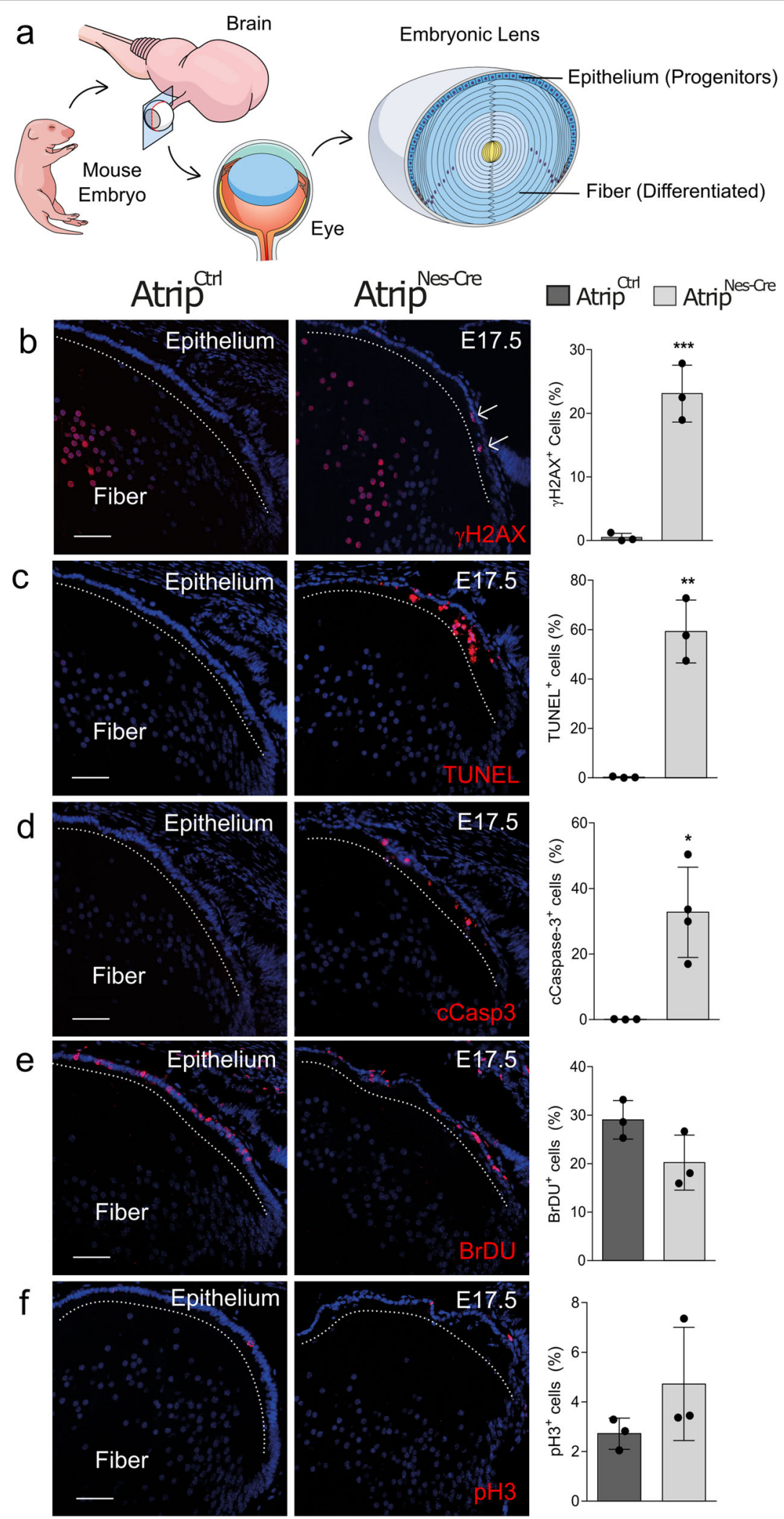

Fig. 3 (See legend on next page.) 
(see figure on previous page)

Fig. 3 Inactivation of Atrip leads to DNA damage response and cell death in lens progenitor cells. a Schematic representation of the developing mouse lens and its cell populations. Representative images and quantifications of E17.5 eye sections from control (Atrip ${ }^{\text {Ctrl }}$ ) and Atripdeficient (Atrip ${ }^{\text {Nes-Cre }}$ ) mice stained for $\mathrm{YH2AX}(\mathbf{b})$, TUNEL (c), cleaved caspase-3 (cCasp3) (d), BrdU (e) and pH3 (f) are shown. Arrows indicate positive

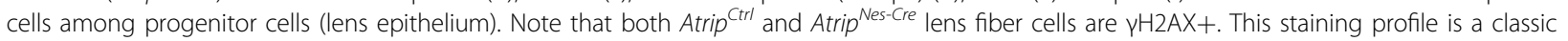
hallmark of lens differentiation (Cvkel et al.; Cavalheiro et al.). The number of biological samples analyzed is represented as the dots in the graphs. Statistical analysis: Student's $t$-test. ${ }^{*} p<0.05 ;{ }^{* *} p<0.01 ;{ }^{* * *} p<0.001$. Scale bar: $100 \mu \mathrm{m}$.

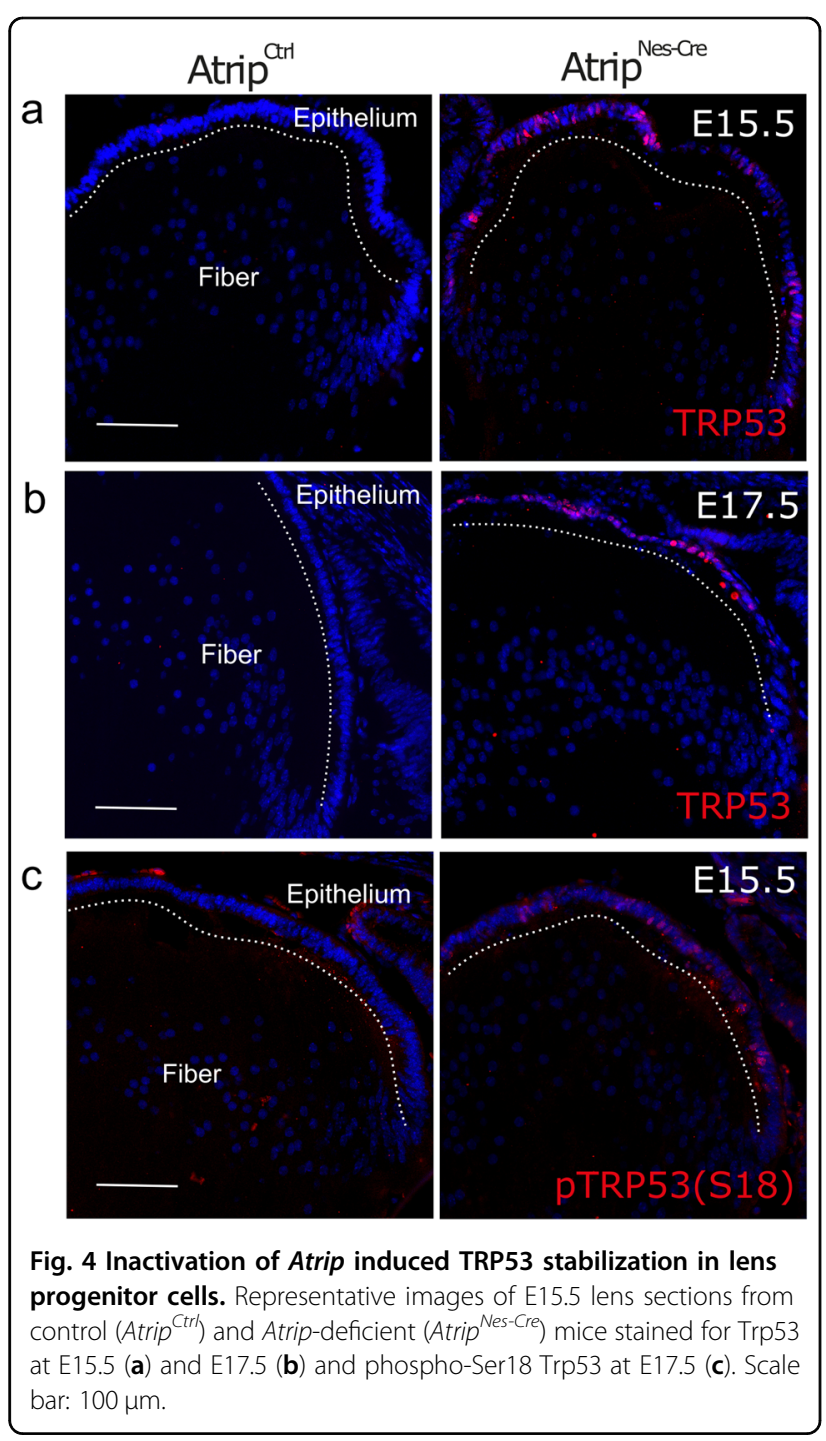

\section{Simultaneous inactivation of Atrip and Trp53 induces mitotic defects}

To test whether the simultaneous inactivation of Atrip and Trp53 affects the DDR in progenitor cells, we scored the proportion of $\gamma \mathrm{H} 2 \mathrm{AX}+$ cells. Interestingly, even though Trp53 inactivation abrogated the cell death induced by ATRIP loss, the proportion of $\gamma \mathrm{H} 2 \mathrm{AX}+$ progenitor cells was similar in Atrip ${ }^{\text {Nes-Cre }}$ and Atrip;
Trp53 $3^{\text {Nes-Cre }}$ mice (E15.5) (Fig. 6a). This finding suggests that DDR activation is not altered after the inactivation of both Atrip and Trp53.

The ATRIP-ATR signaling pathway regulates faithful DNA replication, and its misregulation leads to replicative stress $^{4}$. Next, we examined whether ATRIP loss in the lens progenitor cells would increase DDR activation during S-phase by performing $\gamma \mathrm{H} 2 \mathrm{AX}$ and BrdU double staining. Consistent with the idea that Atrip inactivation increases replicative stress in lens progenitor cells, $~ 17 \%$ of the BrdU-incorporating cells presented $\gamma \mathrm{H} 2 \mathrm{AX}$ staining after ATRIP loss, while only $\sim 0.5 \%$ were double positive in Atrip ${ }^{\text {Ctrl }}$. Moreover, cDKO and cKO lenses presented similar proportion of $\gamma \mathrm{H} 2 \mathrm{AX}$ and BrdU doublepositive cells, showing that TP53 loss did not affect DDR activation following ATRIP loss in replicating progenitor cells (Fig. 6b).

Studies have shown that $A T R$ inactivation leads to the accumulation of mitotic defects in transformed cell lines ${ }^{4,36}$. To determine whether ATRIP loss induces DNA damage accumulation in lens mitotic cells, we evaluated E15.5 lenses double stained with $\gamma \mathrm{H} 2 \mathrm{AX}$ and $\mathrm{pH}$. ATRIP loss induced a 12-fold increase in the proportion of $\gamma \mathrm{H} 2 \mathrm{AX}+$ cells within mitotic cells. Strikingly, while $~ 18 \%$ of mitotic cells were $\gamma \mathrm{H} 2 \mathrm{AX}+$ in Atrip $^{\text {Nes-Cre }}$ mice, in the cDKO lens, we observed a further increase $(\sim 45 \%)$ in mitotic cells accumulating DNA damage at E15.5. These findings indicate that the concomitant inactivation of Trp53 and Atrip increased the accumulation of DNA damage in mitotic progenitors (Fig. 6c).

Finally, we tested whether the increased DNA damage is correlated with the accumulation of mitotic defects (bridges, multiple spindle pole formation and fragmented chromosomes). In the control lens, only $\sim 1.5 \%$ of mitotic cells presented defects, while $\sim 5 \%$ of mitotic cells exhibited defects following Atrip inactivation. Remarkably, a much higher proportion of mitotic cells $(\sim 15 \%)$ presented defects in the cDKO lens epithelium (Fig. 6d). Altogether, these findings suggest that in the absence of TRP53, some Atrip-deficient lens progenitor cells may escape the S/M checkpoint, enter mitosis, accumulate more DNA damage and eventually die during mitosis. Accordingly, double $\mathrm{pH} 3$ and TUNEL staining revealed apoptotic cells during mitosis in the cDKO lens at E15.5 (Fig. 6e). Interestingly, although the concomitant inactivation of Atrip and Trp53 


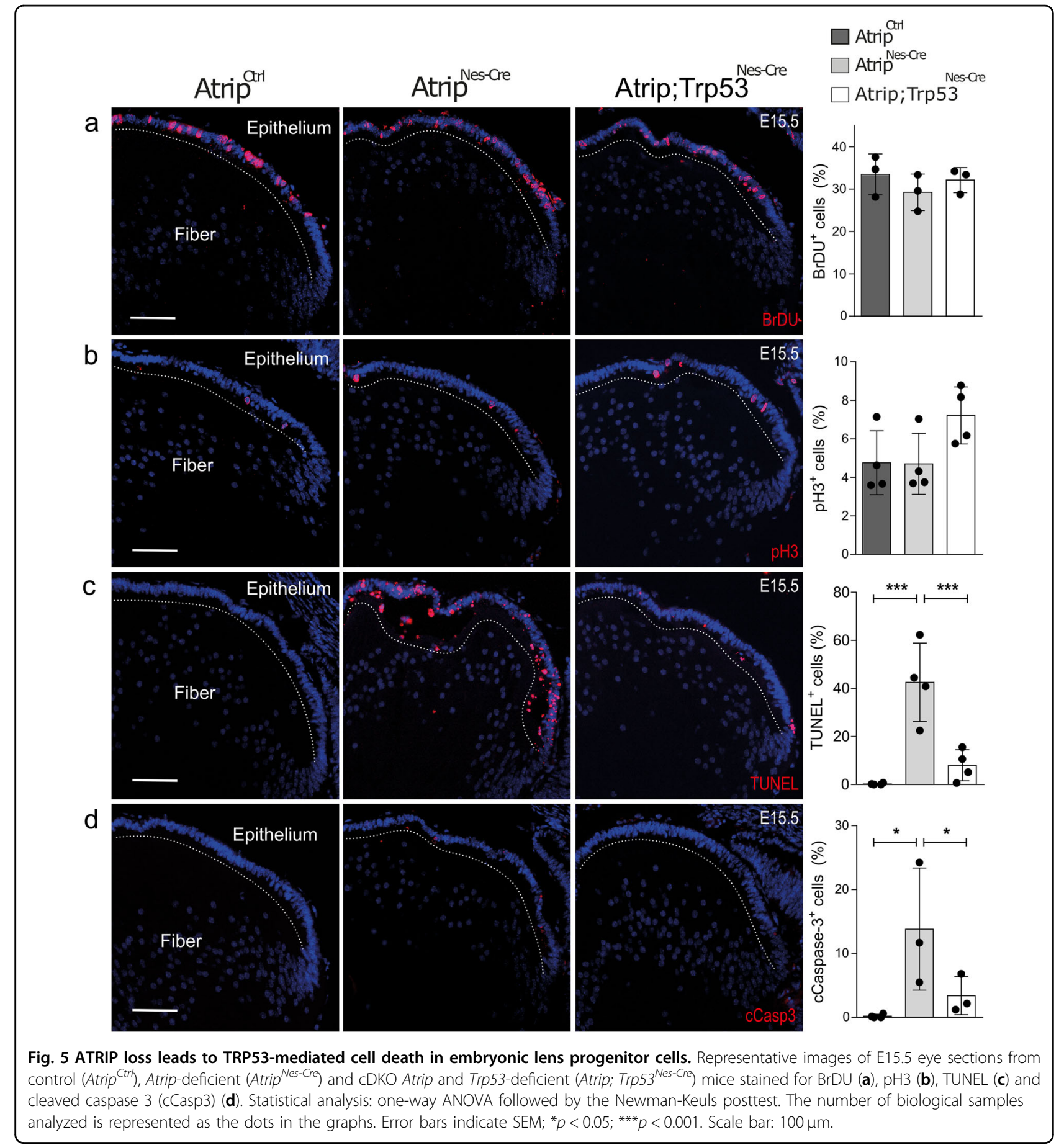

reverted apoptosis induced by ATRIP loss, the eye volume of $\mathrm{cKO}$ and $\mathrm{cDKO}$ mice was similar at P7 (Fig. 6f). Moreover, body and brain weight were not fully rescued in the cDKO mice at P13 (Supplementary Fig. 5). Therefore, Trp53 inactivation is not sufficient to rescue the eye growth impairment caused by ATRIP deficiency. We conclude that, although TRP53 is able to rescue cell death, double inactivation of Atrip and Trp53 increases mitotic defects and does not rescue eye growth defects observed after Atrip inactivation.

\section{Discussion}

Our data demonstrate that ATRIP is essential for CNS and eye development and that ATRIP protected progenitor cells from endogenous DNA damage. We found that a few days after Cre-mediated Atrip inactivation 


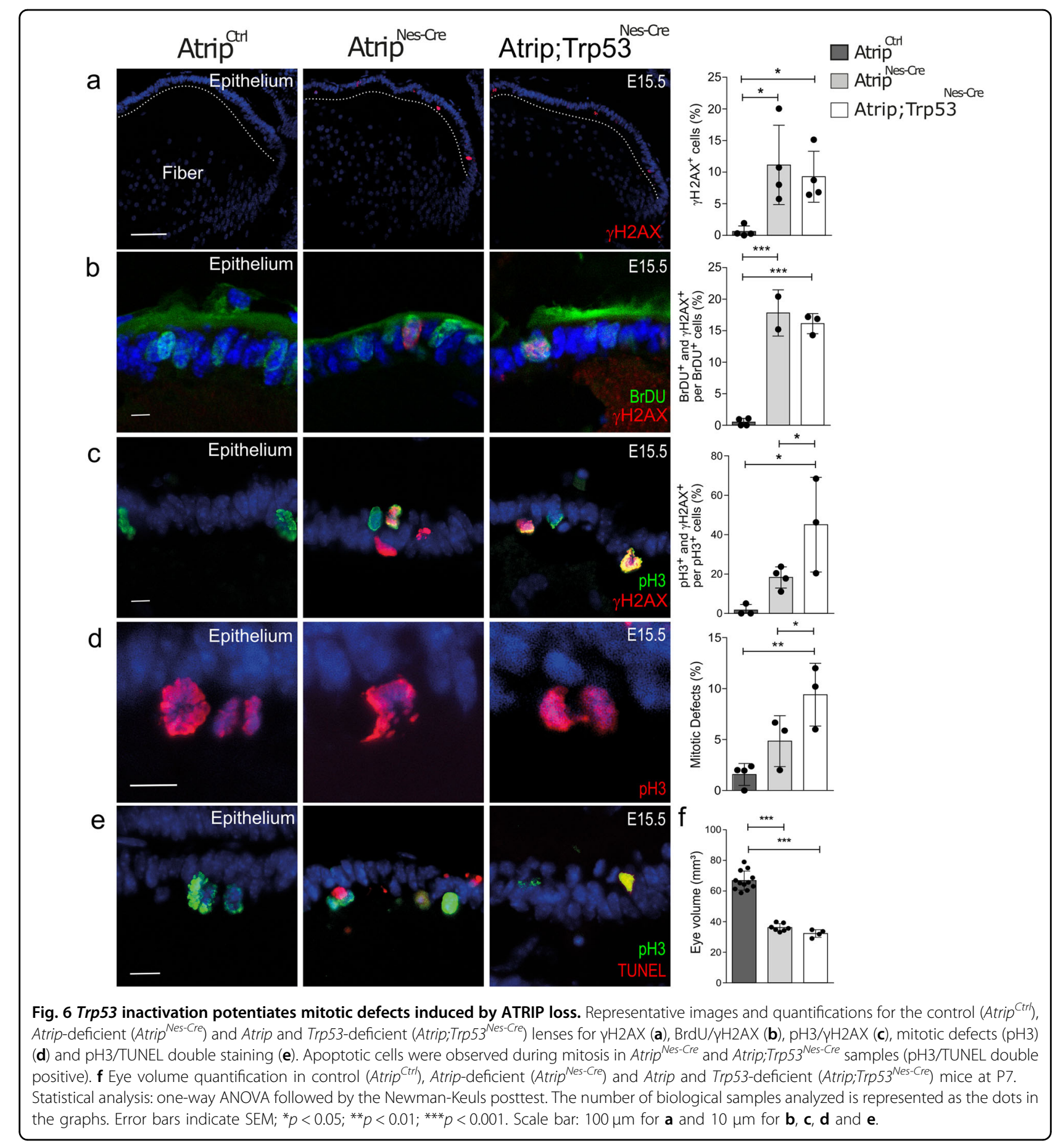

( $\sim 3$ days, at E15.5), lens progenitor cells underwent TRP53-dependent cell death during S-phase. Although Trp53 inactivation rescued the apoptosis induced by ATRIP loss, DNA damage signaling was similar in Atripdeficient and $\mathrm{cDKO}$ lens progenitor cells. In the absence of Trp53, Atrip-deficient lens progenitor cells survived through S-phase and showed increased accumulation of DNA damage and chromosomal defects in mitotic cells.
Few of these cDKO progenitor cells died during mitosis, most likely due to the increased accumulation of DNA damage and, possibly, mitotic crisis. Accordingly, even though Trp53 inactivation rescued the apoptosis caused by ATRIP loss, eye growth impairment was not reversed in cDKO mice. Taken together, our data demonstrate that the ATRIP-ATR complex is essential for protecting progenitor cells against endogenous DNA damage (Fig. 7). 


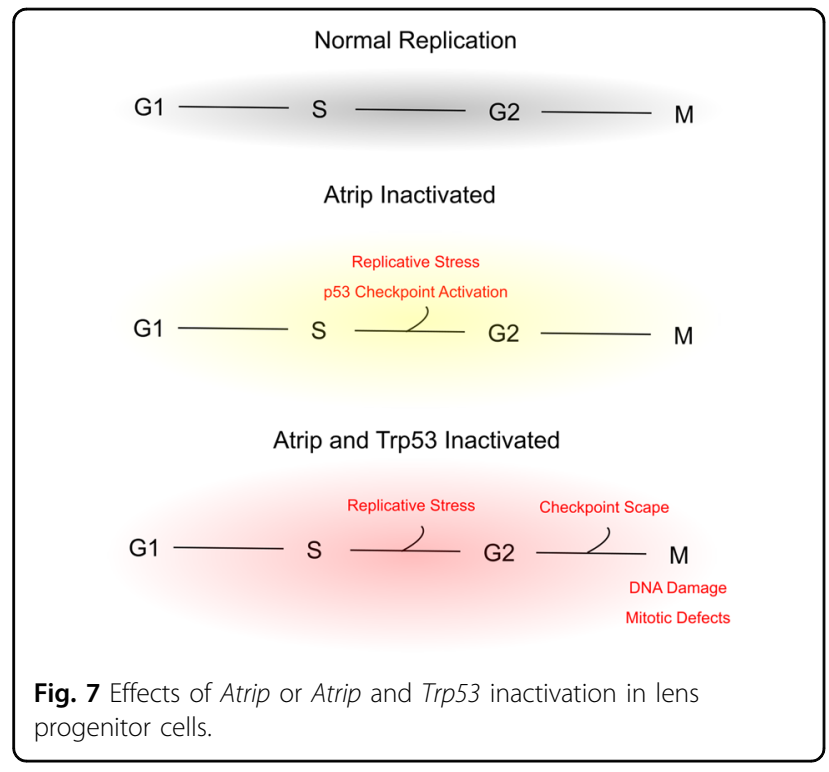

Tissue growth defects are one of the main characteristics of Seckel syndrome patients, including facial dysmorphisms, microcephaly and ophthalmological defects $^{37-40}$. Prior to our study, there was a lack of data supporting the idea that ATRIP could play a role during development. Here, we report the first mouse model of ATRIP loss of function. Atrip inactivation in the CNS and eye led to developmental growth impairment, including microphthalmia and microcephaly, mirroring those associated with ATR loss ${ }^{12}$. Moreover, Atrip inactivation decreased the ATR protein content, establishing a direct connection between ATRIP and ATR function in vivo. In summary, the role of ATRIP during development supports its relationship with Seckel syndrome etiology.

In the absence of ATRIP function, we observed increased activation of the DDR, as revealed by $\gamma \mathrm{H} 2 \mathrm{AX}$ and phospho-TRP53 staining. Following DSB formation, both ATM and DNA-PK are able to phosphorylate these targets $^{34,41,42}$. Although we did not determine which kinase was activated following ATRIP loss, our findings are consistent with the formation of DSBs and activation of ATM or DNA-PK or both. Nevertheless, it was shown that even in the absence of the three main DDR kinases (ATM, ATR and DNA-PK), $\gamma \mathrm{H} 2 \mathrm{AX}$ phosphorylation and TRP53 activation are still detected, therefore we cannot exclude alternative pathways ${ }^{43}$.

Studies in cell lines established that ATR and ATRIP are mutually dependent partners ${ }^{8,29}$. Our findings corroborate that ATRIP is required for ATR protein stability also resulting in the lack of the ATR/ATRIP complex. Therefore, it is challenging to distinguish independent functions of ATR and ATRIP in vivo. The depletion of the ATRIP-ATR complex was shown to increase under- replicated DNA, causing the accumulation of mitotic defects $^{4,44}$, therefore, it is possible that the presence of under-replicated DNA during S-phase leads to the mitotic defects observed in Atrip-deficient progenitor cells. In this scenario, Atrip and Trp53 double inactivation would increase the number of cells that are able to reach mitosis with under-replicated DNA, inducing a further increase in progenitors with mitotic defects. However, we cannot exclude the possibility of mitotic-specific roles of the ATRIP-ATR complex and TRP53. In fact, recent findings indicate that ATR is important for proper chromosomal segregation in cell lines ${ }^{5,36}$. Further studies are necessary to investigate the cell cycle phase-specific contributions of ATRIP -ATR and TRP53 during unchallenged replication in vivo.

Atr inactivation compromises the development of the cerebellum, which is associated with the accumulation of mitotic defects ${ }^{12,19}$. Interestingly, in contrast to what we observed in the developing lens, Trp53 inactivation did not rescue the cell death or the increase in mitotic DNA damage induced by ATR loss in cerebellar progenitor cells $^{19}$. On the other hand, it was shown that TP53-deficient chronic lymphocytic leukemia (CLL) cells displayed an increase in mitotic defects after ATR inhibition ${ }^{45}$. In addition, the accumulation of mitotic defects following $A T R$ inactivation was also shown in transformed cell lines ${ }^{46}$. These data indicate that ATRIP-ATR inactivation may have different outcomes depending on the cell type and genetic background. Since the ATRIP-ATR pathway is activated by replicative stress, we hypothesize that the levels of endogenous replicative stress may be at least partly responsible for these cell type-specific effects.

Currently, different ATR inhibitors are being successfully implemented in preclinical and clinical trials as monotherapy or in combination with other DNAdamaging drugs ${ }^{47,48}$, highlighting the relevance of studying the roles of the ATRIP-ATR complex in vivo. Our data reveal a novel contribution of ATRIP to the avoidance of DNA damage during development and provide a clear picture of the physiological consequences of inhibiting the ATRIP-ATR complex on Trp53 proficient or deficient progenitor cells. The results presented here contribute to the understanding that ATR inhibitors may be toxic to cells with inactivated TP53, what may have important clinical implications.

\section{Acknowledgements}

We thank Josee Guirouilh-Barbat, Emmanuelle Martini, Stephane Koundrioukoff, Leonardo K. Teixeira, Maurício Rocha-Martins and Ales Cvekl for the reading and discussion of the manuscript. We thank Isabele Pio Menezes and Severino Gomes for technical assistance and Dr. Graziela Ventura for assistance in image acquisition at the confocal microscopy facility of the Instituto de Ciências Biomédicas (ICB, UFRJ). This work was supported by the Brazilian National Council of Scientific and Technological Development (CNPq) (425556/2016-6, 439031/2018-4 and 313064/2017-2 to RAPM); FAPERJ (E-26/ 201.562/2014 and E-26/210.500/2019 to RAPM). This work was supported by 
the Deutsche Forschungsgemeinschaft (DFG): FR 2704/1-2 to POF for Initiation of International Collaboration. PG was the recipient of the PET PostDoc Fellowship from "Peter und Traudl Engelhorn Stiftung zur förderung der Biotechnologie und Gentechnik". Open Access funding enabled and organized by Projekt DEAL.

\section{Author details}

${ }^{1}$ Programa de Biologia Celular e do Desenvolvimento, Instituto de Ciências Biomédicas, Universidade Federal do Rio de Janeiro, Rio de Janeiro, RJ, Brazil. ${ }^{2}$ Clinical Cooperation Unit Neuropathology, German Cancer Research Center (DKFZ), D-69120 Heidelberg, Germany. ${ }^{3}$ Institut Cochin, INSERM U1016, UMR8104 CNRS, Université Paris-Descartes, Equipe Labellisée Lique Contre le Cancer, 24 rue du Faubourg St Jacques, 75014 Paris, France. ${ }^{4}$ Institute of Toxicology, University Medical Center of the Johannes Gutenberg University Mainz, Mainz, Germany. ${ }^{5}$ Present address: Institut Cochin, INSERM U1016, UMR8104 CNRS, Université Paris-Descartes, Equipe Labellisée Ligue Contre le Cancer, 24 rue du Faubourg St Jacques, 75014 Paris, France. ${ }^{6}$ Present address: Leibniz Institute on Aging - Fritz Lipmann Institute (FLI), D-07745 Jena, Germany

\section{Author contributions}

G.E.M.R., P.O.F. and R.A.P.M. designed research; G.E.M.R., P.G., P.O.F. and R.A.P.M. performed research; R.A.P.M. and B.S.L. supervised G.E.M.R.; G.E.M.R., P.O.F. and R.A.P.M. wrote the paper; B.S.L. and T.H. performed a critical review of the paper.

\section{Conflict of interest}

The authors declare that they have no conflict of interest.

\section{Publisher's note}

Springer Nature remains neutral with regard to jurisdictional claims in published maps and institutional affiliations.

Supplementary Information accompanies this paper at (https://doi.org/ 10.1038/s41419-020-03090-9).

Received: 21 January 2020 Revised: 29 July 2020 Accepted: 30 July 2020 Published online: 28 October 2020

\section{References}

1. O'Driscoll, M. Diseases associated with defective responses to DNA damage. Cold Spring Harb. Perspect. Biol. 4, https://doi.org/10.1101/cshperspect.a012773 (2012).

2. Jackson, S. P. \& Bartek, J. The DNA-damage response in human biology and disease. Nature 461, 1071-1078 (2009).

3. Ciccia, A. \& Elledge, S. J. The DNA damage response: making it safe to play with knives. Mol. Cell 40, 179-204 (2010).

4. Eykelenboom, J. K. et al. ATR activates the S-M checkpoint during unperturbed growth to ensure sufficient replication prior to mitotic onset. Cell Rep. $\mathbf{5}$, 1095-1107 (2013).

5. Saldivar, J. C. et al. An intrinsic S/G2 checkpoint enforced by ATR. Science $\mathbf{3 6 1}$ 806-810 (2018).

6. Cimprich, K. A. \& Cortez, D. ATR: an essential regulator of genome integrity Nat. Rev. Mol. Cell Biol. 9, 616-627 (2008).

7. Saldivar, J. C., Cortez, D. \& Cimprich, K. A. The essential kinase ATR: ensuring faithful duplication of a challenging genome. Nat. Rev. Mol. Cell Biol. 18, 622-636 (2017).

8. Cortez, D., Guntuku, S., Qin, J. \& Elledge, S. J. ATR and ATRIP: partners in checkpoint signaling. Science 294, 1713-1716, https:/doi.org/10.1126/ science.1065521 (2001).

9. Brown, E. J. \& Baltimore, D. ATR disruption leads to chromosomal fragmentation and early embryonic lethality. Genes Dev. 14, 397-402 (2000).

10. de Klein, A. et al. Targeted disruption of the cell-cycle checkpoint gene ATR leads to early embryonic lethality in mice. Curr. Biol. 10, 479-482 (2000).

11. O'Driscoll, M. Mouse models for ATR deficiency. DNA Repair 8, 1333-1337 (2009).

12. Lee, Y. et al. ATR maintains select progenitors during nervous system development. EMBO J. 31, 1177-1189 (2012).
13. Ruzankina, Y. et al. Deletion of the developmentally essential gene ATR in adult mice leads to age-related phenotypes and stem cell loss. Cell Stem Cell $\mathbf{1}$, 113-126 (2007).

14. Royo, $\mathrm{H}$. et al. ATR acts stage specifically to regulate multiple aspects of mammalian meiotic silencing. Genes Dev. 27, 1484-1494 (2013).

15. Murga, M. et al. A mouse model of ATR-Seckel shows embryonic replicative stress and accelerated aging. Nat. Genet 41, 891-898 (2009).

16. Meek, D. W. Tumour suppression by p53: a role for the DNA damage response? Nat. Rev. Cancer 9, 714-723 (2009).

17. Kaiser, A. M. \& Attardi, L. D. Deconstructing networks of p53-mediated tumor suppression in vivo. Cell Death Differ. 25, 93-103 (2018).

18. Frappart, P. O. \& McKinnon, P. J. Mouse models of DNA double-strand break repair and neurological disease. DNA Repair 7, 1051-1060 (2008).

19. Lang, P. Y. et al. ATR maintains chromosomal integrity during postnatal cerebellar neurogenesis and is required for medulloblastoma formation. Development 143, 4038-4052 (2016).

20. Murga, M. et al. Exploiting oncogene-induced replicative stress for the selective killing of Myc-driven tumors. Nat. Struct. Mol. Biol. 18, 1331-1335 (2011).

21. Kawasumi, M. et al. Identification of ATR-Chk1 pathway inhibitors that selectively target p53-deficient cells without directly suppressing ATR catalytic activity. Cancer Res. 74, 7534-7545 (2014).

22. Morgado-Palacin, I. et al. Targeting the kinase activities of ATR and ATM exhibits antitumoral activity in mouse models of MLL-rearranged AML. SCi Signal 9, ra91 (2016).

23. Cvekl, A. \& Ashery-Padan, R. The cellular and molecular mechanisms of vertebrate lens development. Development 141, 4432-4447 (2014).

24. Morgenbesser, S. D., Williams, B. O., Jacks, T. \& DePinho, R. A. p53-dependent apoptosis produced by Rb-deficiency in the developing mouse lens. Nature 371, 72-74 (1994).

25. Martins, R. A. et al. N-myc coordinates retinal growth with eye size during mouse development. Genes Dev. 22, 179-193 (2008).

26. Cavalheiro, G. R., Matos-Rodrigues, G. E., Gomes, A. L., Rodriques, P. M. \& Martins, R. A. c-Myc regulates cell proliferation during lens development. PLOS ONE 9, e87182 (2014).

27. Martins, R. A., Linden, R. \& Dyer, M. A. Glutamate regulates retinal progenitors cells proliferation during development. Eur. J. Neurosci. 24, 969-980 (2006).

28. Yamamoto, A. et al. Cell cycle-dependent expression of the mouse Rad51 gene in proliferating cells. Mol. Gen. Genet. 251, 1-12 (1996).

29. Lin, Y. et al. APE2 promotes DNA damage response pathway from a singlestrand break. Nucleic Acids Res. 46, 2479-2494 (2018).

30. Ashery-Padan, R., Marquardt, T., Zhou, X. \& Gruss, P. Pax6 activity in the lens primordium is required for lens formation and for correct placement of a single retina in the eye. Genes Dev. 14, 2701-2711 (2000).

31. Kreslova, J. et al. Abnormal lens morphogenesis and ectopic lens formation in the absence of beta-catenin function. Genesis 45, 157-168 (2007).

32. Lovicu, F. J. \& McAvoy, J. W. Growth factor regulation of lens development. Dev. Biol. 280, 1-14 (2005).

33. Cvekl, A. \& Zhang, X. Signaling and gene regulatory networks in mammalian lens development. Trends Genet 33, 677-702 (2017).

34. Banin, S. et al. Enhanced phosphorylation of p53 by ATM in response to DNA damage. Science 281, 1674-1677 (1998).

35. Tibbetts, R. S. et al. A role for ATR in the DNA damage-induced phosphorylation of p53. Genes Dev. 13, 152-157 (1999).

36. Kabeche, L., Nguyen, H. D., Buisson, R. \& Zou, L. A mitosis-specific and R loopdriven ATR pathway promotes faithful chromosome segregation. Science 359, 108-114 (2018).

37. Klingseisen, A. \& Jackson, A. P. Mechanisms and pathways of growth failure in primordial dwarfism. Genes Dev. 25, 2011-2024 (2011).

38. Reddy, S. \& Starr, C. Seckel syndrome and spontaneously dislocated lenses. J. Cataract Refract Surg. 33, 910-912 (2007).

39. Krzyzanowska-Berkowska, P., Szumny, D., Mlynczak, T., Kisza, K. \& Oficjalska, J. Bilateral retinal detachment in Seckel syndrome. Can. J. Ophthalmol. 49, e130-e131 (2014)

40. Guirgis, M. F., Lam, B. L. \& Howard, C. W. Ocular manifestations of Seckel syndrome. Am. J. Ophthalmol. 132, 596-597 (2001).

41. Burma, S., Chen, B. P., Murphy, M., Kurimasa, A. \& Chen, D. J. ATM phosphorylates histone H2AX in response to DNA double-strand breaks. J. Biol. Chem. 276, 42462-42467 (2001).

42. Lees-Miller, S. P., Sakaguchi, K., Ullrich, S. J., Appella, E. \& Anderson, C. W. Human DNA-activated protein kinase phosphorylates serines 15 and 37 in the amino- 
terminal transactivation domain of human p53. Mol. Cell Biol. 12, 5041-5049 (1992).

43. Enriquez-Rios, V. et al. DNA-PKcs, ATM, and ATR Interplay Maintains Genome Integrity during Neurogenesis. J. Neurosci. 37, 893-905 (2017).

44. Bhowmick, R., Minocherhomji, S. \& Hickson, I. D. RAD52 facilitates mitotic DNA synthesis following replication stress. Mol. Cell 64, 1117-1126 (2016).

45. Kwok, M. et al. ATR inhibition induces synthetic lethality and overcomes chemoresistance in TP53- or ATM-defective chronic lymphocytic leukemia cells. Blood 127, 582-595 (2016).
46. Bukhari, A. B. et al. Inhibiting Wee1 and ATR kinases produces tumor-selective synthetic lethality and suppresses metastasis. J. Clin. Invest. 129, 1329-1344 (2019).

47. Perkhofer, L. et al. ATM deficiency generating genomic instability sensitizes pancreatic ductal adenocarcinoma cells to therapy-induced DNA damage. Cancer Res. 77, 5576-5590 (2017)

48. Lecona, E. \& Fernandez-Capetillo, O. Targeting ATR in cancer. Nat. Rev. Cancer 18, 586-595 (2018) 